\title{
Reproductive outcomes after laparoscopic radical trachelectomy for early-stage cervical cancer
}

\author{
Jeong-Yeol Park, Dae-Yeon Kim, Dae-Shik Suh, Jong-Hyeok Kim, Yong-Man Kim, Young-Tak Kim, Joo-Hyun Nam \\ Department of Obstetrics and Gynecology, Asan Medical Center, University of Ulsan College of Medicine, Seoul, Korea
}

Objective: The objective of this study was to estimate the reproductive outcome of young women with early-stage cervical cancer who underwent fertility-sparing laparoscopic radical trachelectomy (LRT).

Methods: We performed a retrospective review of the medical records of patients with early-stage cervical cancer who underwent LRT. Clinicopathological data were obtained from patient medical records, and reproductive outcome data were obtained from patient medical records and telephone interviews.

Results: Fifty-five patients who underwent successful LRT were included in this study. The median age of patients was 32 years (range, 22 to 40 years), and the median follow-up time after LRT was 37 months (range, 3 to 105 months). Menstruation resumed in all patients after LRT, with fifty patients (90.9\%) and five patients (9.1\%) reporting regular and irregular menstruation, respectively. Six patients (10.9\%) presented with cervical stenosis, which was manifested by regular but decreased menstrual flow and newly-developed dysmenorrhea. These patients underwent cervical cannulation and dilatation. Eighteen patients (32.7\%) attempted to conceive, with six out of 18 patients receiving fertility treatments. Fourteen pregnancies (i.e., four missed abortions, six preterm births and four full-term births) occurred in 10 patients after LRT. Nine out of 10 patients gave birth to 10 healthy babies. The pregnancy rate after LRT was $55.6 \%$ (10/18). The spontaneous abortion rate and live birth rate were $28.6 \%$ (4/14) and 71.4\% (10/14), respectively. The preterm birth rate was 60\% (6/10).

Conclusion: Pregnancy and live birth rates after LRT were promising; however, the preterm birth rate was relatively high. Cervical stenosis also occurred in a small percentage of patients.

Keywords: Cervical cancer, Fertility, Laparoscopic radical trachelectomy, Pregnancy outcome, Reproductive outcome

\section{INTRODUCTION}

Cervical cancer is the third most common type of cancer in women and the fourth most common cause of cancer death in women worldwide [1]. In Korea, however, it is the seventh most common type of cancer in women and the eighth most common cause of cancer death in women [2]. Due to the introduction of a nationwide screening program for cervical

Received Aug 16, 2013, Revised Sep 17, 2013, Accepted Sep 25, 2013

Correspondence to Joo-Hyun Nam

Department of Obstetrics and Gynecology, Asan Medical Center, University of Ulsan College of Medicine, 88 Olympic-ro 43-gil, Songpa-gu, Seoul 138736, Korea. E-mail: jhnam@amc.seoul.kr cancer in Korea, the incidence of cervical cancer is gradually decreasing, and most cases are diagnosed at an early-stage and treated by radical hysterectomy, which is the standard treatment for cervical cancer [3].

Approximately $20 \%$ of cervical cancers are diagnosed in women who are under 40 years of age and still interested in preserving their fertility [4]. While radical hysterectomy is generally unacceptable for these patients, vaginal radical trachelectomy is a safe and effective alternative for women wishing to preserve their fertility $[5,6]$. To overcome the limitations associated with parametrial resection and the difficulties in learning vaginal radical trachelectomy, abdominal radical trachelectomy has been introduced [5,7]. Another approach, laparoscopic radical trachelectomy (LRT), is also

Copyright (C) 2014. Asian Society of Gynecologic Oncology, Korean Society of Gynecologic Oncology 
a treatment of choice because it is minimally invasive $[8,9]$. The reproductive outcome of patients who underwent either a vaginal or abdominal radical trachelectomy is well known $[5,6,10]$; however, the reproductive outcome of women who underwent LRT is not yet known. The aim of this study was to determine the reproductive outcome of young women with early-stage cervical cancer who underwent LRT.

\section{MATERIALS AND METHODS}

After obtaining approval from the Institutional Review Board of Asan Medical Center (Seoul, Korea), we reviewed the medical records of patients who underwent LRT for early-stage cervical cancer between 2004 and 2012. The inclusion criteria were as follows: (1) the presence of histologically-proven cervical cancer; (2) a cervical cancer histology of squamous cell carcinoma, adenocarcinoma, or adenosquamous carcinoma; (3) an International Federation of Gynecology and Obstetrics (FIGO) stage of IA2 to IB1; (4) a tumor size of $\leq 3 \mathrm{~cm}$; (5) a completed LRT; and (6) an age of $\leq 40$ years. Patients who required an immediate conversion to laparoscopic radical hysterectomy and who received adjuvant radiation or concurrent chemoradiation therapy were excluded.

Clinicopathological data, including patient age, parity, tumor histology, FIGO stage, tumor size, the presence of lymphovascular space or parametrial invasion, the depth of the cervical stromal invasion, the presence of lymph node metastasis, follow-up time, cancer recurrence, and death, were obtained from patient medical records. Reproductive outcome data, including menstruation patterns, fertility treatment, and pregnancy attempts, successes and outcomes, were obtained from patient medical records and telephone interviews.

All patients underwent uterine artery-preserving LRT as previously described $[8,9]$. A cervical cerclage was performed on all patients during LRT. After surgery, patients were followedup on every 3 months during the first two years, every 6 months during the next 3 years, and then once every year.

\section{RESULTS}

Sixty-three patients who met the inclusion criteria were identified. Seven out of 63 patients who underwent immediate conversion to laparoscopic radical hysterectomy and one patient who received adjuvant concurrent chemoradiation therapy were excluded. The remaining 55 patients were included in this study.

Table 1 lists patient characteristics. The median age of patients was 32 years (range, 22 to 40 years). Three patients (5.4\%) with a high risk of recurrence received adjuvant chemotherapy consisting of six cycles of paclitaxel $\left(175 \mathrm{mg} / \mathrm{m}^{2}\right) /$ carboplatin (area under curve 5) after surgery. Menstruation resumed in all patients after LRT, with 50 patients (90.9\%) and five patients (9.1\%) reporting regular and irregular menstruation, respectively. Six patients (10.9\%) presented with cervical stenosis, which was manifested by regular but decreased menstrual flow and newly-developed dysmenorrhea. These patients underwent transvaginal cannulation of the cervical canal under general or local anesthesia. One patient also required laparoscopic surgery to guide the transvaginal cannulation of the cervical canal. Cannulation abrogated symptoms in all patients, except in one who had a recurrence of cervical stenosis and had to undergo a second cannulation.

Table 2 lists patient pregnancy outcomes. Thirty-two patients (58.2\%) were married at the time of this analysis. Eighteen patients (32.7\%) attempted to conceive after LRT, and 10 patients succeeded in 14 pregnancies. Thus, the pregnancy rate after LRT was $55.6 \%$ (10/18). Six out of 18 patients received fertility treatments, resulting in five pregnancies after fertility treatments and nine natural pregnancies. The causes of infertility were ovarian factor in four patients and unknown in two patients. There were four missed abortions, six preterm

Table 1. Patient characteristics $(n=55)$

\begin{tabular}{lc}
\hline \multicolumn{1}{c}{ Characteristic } & No. (\%) \\
\hline Age (yr), median (range) & $32(22-40)$ \\
Parity & \\
0 & $44(80)$ \\
1 & $7(12.7)$ \\
2 & $4(7.3)$ \\
FIGO stage & \\
IA2 & $2(3.6)$ \\
IB1 & $53(96.4)$ \\
Tumor histology & \\
Squamous cell carcinoma & $42(76.4)$ \\
Adenocarcinoma & $13(23.6)$ \\
Tumor size (cm), median (range) & $1.4(0.4-3)$ \\
Depth of stromal invasion & \\
$<1 / 3$ & $36(65.5)$ \\
1/3-2/3 & $15(27.3)$ \\
$>2 / 3$ & $4(7.3)$ \\
Lymphovascular space invasion & $5(9.1)$ \\
Parametrial invasion & $2(3.6)$ \\
Lymph node metastasis & $2(3.6)$ \\
\hline
\end{tabular}

FIGO, International Federation of Gynecology and Obstetrics. 
Table 2. Obstetric outcomes of eighteen patients who attempted to conceive after laparoscopic radical trachelectomy for early-stage cervical cancer

\begin{tabular}{|c|c|c|c|c|c|c|c|}
\hline $\begin{array}{l}\text { Case } \\
\text { no. }\end{array}$ & $\begin{array}{c}\text { Age at } \\
\text { gestation } \\
(y r)\end{array}$ & $\begin{array}{l}\text { Cervical } \\
\text { stricture }\end{array}$ & $\begin{array}{l}\text { Conception } \\
\text { method }\end{array}$ & $\begin{array}{l}\text { Success in } \\
\text { pregnancy }\end{array}$ & $\begin{array}{l}\text { Gestational } \\
\text { age (wk) }\end{array}$ & Pregnancy outcome & Obstetric complications \\
\hline 1 & 22 & No & Natural & Yes & 6 & Spontaneous abortion & Spontaneous abortion \\
\hline 2 & 24 & Yes & IVF-ET & Not yet & - & - & - \\
\hline 3 & 25 & No & Natural & Not yet & - & - & - \\
\hline 4 & 26 & No & IUI & Not yet & - & - & - \\
\hline \multirow[t]{2}{*}{5} & 26 & No & Natural & Yes & 7 & Spontaneous abortion & Spontaneous abortion \\
\hline & & & Natural & Yes & 36 & Preterm birth at $32-36 \mathrm{wk}, \mathrm{C} / \mathrm{sec}$ & Preterm labor \\
\hline \multirow[t]{2}{*}{6} & 26 & No & IUI & Yes & 6 & Spontaneous abortion & Spontaneous abortion \\
\hline & & & IVF-ET & Yes & 28 & Preterm birth at $23-28 \mathrm{wk}, \mathrm{C} / \mathrm{sec}$ & PPROM, Breech presentation \\
\hline 7 & 27 & Yes & IUI & Yes & 37 & Term birth, C/hysterectomy & Obstetric bleeding \\
\hline 8 & 27 & No & Natural & Not yet & - & - & - \\
\hline \multirow[t]{2}{*}{9} & 27 & No & Natural & Yes & 38 & Term birth, C/sec & None \\
\hline & & & Natural & Yes & 36 & Preterm birth at 32-36 wk, C/hysterectomy & PPROM, Obstetric bleeding \\
\hline \multirow[t]{2}{*}{10} & 29 & No & Natural & Yes & 6 & Spontaneous abortion & Spontaneous abortion \\
\hline & & & $\mathrm{COH}-\mathrm{IUI}$ & Yes & 28 & Preterm birth at $23-28 \mathrm{wk}, \mathrm{C} / \mathrm{sec}$ & PPROM, GDM type A1 \\
\hline 11 & 29 & No & $\mathrm{COH}-\mathrm{IUI}$ & Yes & 36 & Preterm birth at $32-36 \mathrm{wk}, \mathrm{C} / \mathrm{sec}$ & PPROM, Placenta accreta* \\
\hline 12 & 30 & No & Natural & Yes & 37 & Term birth, C/sec & None \\
\hline 13 & 31 & No & Natural & Not yet & - & - & - \\
\hline 14 & 32 & No & Natural & Yes & 36 & Preterm birth at 32-36 wk, C/sec & Preterm labor \\
\hline 15 & 32 & No & Natural & Not yet & - & - & - \\
\hline 16 & 34 & No & Natural & Not yet & - & - & - \\
\hline 17 & 34 & No & Natural & Yes & 37 & Term, C/sec & None \\
\hline 18 & 36 & No & Natural & Not yet & - & - & - \\
\hline
\end{tabular}

$\mathrm{COH}-\mathrm{IUI}$, controlled ovarian hyperstimulation-intrauterine insemination; C/hysterectomy, Cesarean hysterectomy; C/sec, Cesarean section; GDM, gestational diabetes mellitus; IUI, intrauterine insemination; IVF-ET, in vitro fertilization-embryo transfer; PPROM, preterm premature rupture of membrane.

*Uterine artery embolization was done due to obstetric hemorrhage.

births, and four full-term births. Nine out of 10 patients gave birth to 10 healthy babies. The spontaneous abortion rate and live birth rate among 14 pregnancies were 28.6\% (4/14) and $71.4 \%(10 / 14)$, respectively. The preterm birth rate was $60 \%(6 / 10)$. All babies were delivered by cesarean section. The preterm premature rupture of membranes was complicated in four pregnancies and the preterm labor was complicated in two pregnancies. Each one patient had type A1 gestational diabetes mellitus, placenta accreta, and breech presentation, respectively. Two patients underwent cesarean hysterectomy, and one patient underwent uterine artery embolization due to obstetric bleeding after the cesarean section.

\section{DISCUSSION}

We report the reproductive outcome in young women with early-stage cervical cancer after fertility-sparing LRT. Menstrua- tion resumed in all patients after surgery. Pregnancy and live birth rates were $55.6 \%$ and $71.4 \%$, respectively, illustrating that the reproductive outcome after LRT is promising. Unlike vaginal and abdominal radical trachelectomies, the pregnancy outcome after LRT is largely unknown because the procedure is surgically challenging. Several studies report 27 pregnancies out of 110 patients who underwent LRT (Table 3) [11-19]. Our report is, to our knowledge, one of the largest studies on reproductive outcome after LRT.

The pregnancy rate of patients who attempted to conceive after vaginal or abdominal radical trachelectomy was $52.8 \%$ [20] and 59.3\% [7], respectively. These results are comparable with the pregnancy rate $(55.6 \%)$ reported in our study. Moreover, the live birth rate of patients who achieved a pregnancy after vaginal or abdominal radical trachelectomy was $68.9 \%$ [21] and $70.1 \%$ [7], respectively. These results are also comparable with the live birth rate reported in our study (71.4\%).

The pregnancy loss rate after vaginal and abdominal radical 
Table 3. Pregnancy outcomes after laparoscopic radical trachelectomy for early-stage cervical cancer in published studies

\begin{tabular}{|c|c|c|c|c|c|c|c|}
\hline Author (year) & $\begin{array}{c}\text { No. of } \\
\text { patients }\end{array}$ & Age (yr) & Pregnancy & $\begin{array}{l}\text { Spontaneous } \\
\text { abortion }\end{array}$ & Preterm birth & Term birth & $\begin{array}{l}\text { Ongoing } \\
\text { pregnancy }\end{array}$ \\
\hline Pomel et al. (2002) [11] & 7 & NR & NR & NR & NR & NR & NR \\
\hline Lee et al. (2003) [12] & 2 & 30,34 & NR & NR & NR & NR & NR \\
\hline Cibula et al. (2005) [13] & 1 & 36 & NR & NR & NR & NR & NR \\
\hline Bafghi et al. (2006) [14] & 6 & 30 & 2 & 1 & 0 & 1 & 0 \\
\hline Martin and Torrent (2010) [15] & 9 & 32 & 2 & 0 & 0 & 1 & 1 \\
\hline Wang et al. (2011) [16] & 1 & 30 & 0 & 0 & 0 & 0 & 0 \\
\hline Hong et al. (2011) [17] & 4 & $29.5(25-33)$ & NR & NR & NR & NR & NR \\
\hline Rendon et al. (2012) [18] & 1 & 30 & 0 & 0 & 0 & 0 & 0 \\
\hline Lu et al. (2013) [19] & 24 & $29(22-34)$ & 9 & 3 & 1 & 3 & 2 \\
\hline Present study & 55 & $32(22-40)$ & 14 & 4 & 6 & 4 & 0 \\
\hline
\end{tabular}

NR, not reported.

trachelectomy was 24\% [21] and 24\% [7], respectively, comparable with $28.6 \%$ after LRT. However, these rates are significantly higher than that of the general population (12\%) [22].

The preterm birth rate of patients who gave birth after a vaginal or abdominal radical trachelectomy was $24.7 \%$ [21] and $38.7 \%$ [7], respectively. However, the preterm birth rate after LRT was $60 \%$ in our study. However, in the present series, four of six preterm deliveries was at 36 weeks of gestational age and only two preterm deliveries were at 28 weeks of gestational age. Usually, deliveries after 32-34 weeks of gestational age are associated with excellent perinatal outcomes. Furthermore, deliveries after 36 weeks of gestational age have similar perinatal outcomes with term deliveries. Therefore, we think that only two preterm deliveries $(10 \%, 2 / 10)$ at 28 weeks of gestational age are problematic at present series. Regardless of the type of radical trachelectomy, the preterm birth rate was higher than that of the general population (10\%) [23]. Preterm premature rupture of membranes was the most common obstetric complication encountered by these patients $[7,21]$. Unfortunately, the excision of cervical tissues during radical trachelectomy increases the risk of preterm premature rupture of membranes and spontaneous preterm labor because it may reduce the mechanical support of cervix, impair local immunological defense mechanisms, and alter cervicovaginal bacterial flora [24]. However, the live birth rate after radical trachelectomy is promising, despite the high frequency of preterm delivery.

Cervical stenosis is the most common postoperative complication after radical trachelectomy [7]. It occurs in 10\% [6] and $9.5 \%$ [7] of patients who underwent vaginal and abdominal radical trachelectomies, respectively. In our study, cervical stenosis occurred in $10.9 \%$ of patients. While cervical stenosis can be asymptomatic, it can associate with infertility and cryptomenorrhea with pain. It usually requires cervical dilatation under general anesthesia to abrogate symptoms and to achieve a pregnancy. In some cases, cervical cannulation and dilatation requires laparoscopic or ultrasonographic guidance [25]. Recurrence can occur, requiring two or three consecutive cannulations and dilatation of the cervix. Several methods to prevent cervical stenosis are currently in practice, including insertion of an intrauterine device and cervical dilators. However, the efficacy of these methods is unclear [26].

In the present series, we excluded patients who required conversion to radical hysterectomy or adjuvant chemoradiation therapy. The exclusion of these patients may biases the results. However, if these patients are included in the analysis of fertility outcomes, the fertility outcomes may be underestimated because radical hysterectomy or adjuvant chemoradiation therapy cause permanent infertility and these patients may not attempt to conceive. Therefore, we excluded these patients in the analysis of fertility outcomes and included only patients who underwent successful LRT.

In conclusion, the reproductive outcome of patients after LRT appears to be similar with those who underwent vaginal or abdominal radical trachelectomy. Pregnancy and live birth rates were promising after LRT; however, the preterm birth rate was relatively high. Cervical stenosis also occurred in a small percentage of patients.

\section{CONFLICT OF INTEREST}

Jeong-Yeol Park and Joo Hyun Nam serves as Editor and Editorial Advisor of the JGO respectively but has no role in the decision to publish this article. No other conflict of interest relevant to this article was reported. 


\section{REFERENCES}

1. Jemal A, Bray F, Center MM, Ferlay J, Ward E, Forman D. Global cancer statistics. CA Cancer J Clin 2011;61:69-90.

2. Jung KW, Won YJ, Kong HJ, Oh CM, Seo HG, Lee JS. Cancer statistics in Korea: incidence, mortality, survival and prevalence in 2010. Cancer Res Treat 2013;45:1-14.

3. Lee YH, Choi KS, Lee HY, Jun JK. Current status of the National Cancer Screening Program for cervical cancer in Korea, 2009. J Gynecol Oncol 2012;23:16-21.

4. Lee HP. Annual report of gynecologic cancer registry program in Korea: 1991 2004. Korean J Obstet Gynecol 2008;51:1411-20.

5. Rob L, Skapa P, Robova H. Fertility-sparing surgery in patients with cervical cancer. Lancet Oncol 2011;12:192-200.

6. Plante M, Gregoire J, Renaud MC, Roy M. The vaginal radical trachelectomy: an update of a series of 125 cases and 106 pregnancies. Gynecol Oncol 2011;121:290-7.

7. Pareja R, Rendon GJ, Sanz-Lomana CM, Monzon O, Ramirez PT. Surgical, oncological, and obstetrical outcomes after abdominal radical trachelectomy: a systematic literature review. Gynecol Oncol 2013;131:77-82.

8. Chang SJ, Ryu HS, Nam JH. Uterine artery-preserving laparoscopic radical trachelectomy for early cervical cancer: technical aspects. Gynecol Oncol 2012;126:277-8.

9. Kim JH, Park JY, Kim DY, Kim YM, Kim YT, Nam JH. Fertility-sparing laparoscopic radical trachelectomy for young women with early stage cervical cancer. BJOG 2010;117:340-7.

10. Nishio H, Fujii T, Sugiyama J, Kuji N, Tanaka M, Hamatani T, et al. Reproductive and obstetric outcomes after radical abdominal trachelectomy for early-stage cervical cancer in a series of 31 pregnancies. Hum Reprod 2013;28:1793-8.

11. Pomel C, Castaigne D, Atallah D, Lauratet B, Camatte S, Morice $\mathrm{P}$, et al. Laparoscopic (type III Piver like) radical trachelectomy [abstract]. Eur J Surg Oncol 2002;28:302.

12. Lee $\mathrm{CL}$, Huang KG, Wang CJ, Yen CF, Lai CH. Laparoscopic radical trachelectomy for stage Ib1 cervical cancer. J Am Assoc Gynecol Laparosc 2003;10:111-5.

13. Cibula D, Ungar L, Palfalvi L, Bino B, Kuzel D. Laparoscopic abdominal radical trachelectomy. Gynecol Oncol 2005;97:707-9.

14. Bafghi A, Castaigne D, Pomel C. Radical trachelectomy: from the laparoscopic approach to the vaginal route. J Gynecol Obstet
Biol Reprod (Paris) 2006:35:696-701.

15. Martin A, Torrent A. Laparoscopic nerve-sparing radical trachelectomy: surgical technique and outcome. J Minim Invasive Gynecol 2010;17:37-41.

16. Wang YF, Chen GW, Li WS, Weng HN, Lu XG. Total laparoscopic radical trachelectomy with ascending branches of uterine arteries preservation. Chin Med J (Engl) 2011;124:469-71.

17. Hong DG, Lee YS, Park NY, Chong GO, Park IS, Cho YL. Robotic uterine artery preservation and nerve-sparing radical trachelectomy with bilateral pelvic lymphadenectomy in early-stage cervical cancer. Int J Gynecol Cancer 2011;21:391-6.

18. Rendon GJ, Ramirez PT, Frumovitz M, Schmeler KM, Pareja R. Laparoscopic radical trachelectomy. JSLS 2012;16:503-7.

19. Lu Q, Zhang Y, Liu C, Wang S, Guo S, Zhang Z. Total laparoscopic radical trachelectomy in the treatment of early squamous cell cervical cancer: a retrospective study with 8-year follow-up. Gynecol Oncol 2013;130:275-9.

20. Shepherd JH, Spencer C, Herod J, Ind TE. Radical vaginal trachelectomy as a fertility-sparing procedure in women with early-stage cervical cancer-cumulative pregnancy rate in a series of 123 women. BJOG 2006;113:719-24.

21. Plante M. Evolution in fertility-preserving options for early-stage cervical cancer: radical trachelectomy, simple trachelectomy, neoadjuvant chemotherapy. Int J Gynecol Cancer 2013;23:982-9.

22. Regan L, Braude PR, Trembath PL. Influence of past reproductive performance on risk of spontaneous abortion. BMJ 1989;299:5415.

23. Preterm birth. In: Cunningham FG, Gant NF, Leveno KJ, Gilstrap LC 3rd, Hauth JC, Wenstrom KD, editors. Williams obstetrics. 21st ed. New York: McGraw-Hill; 2001. p. 689-727.

24. Svare JA, Andersen LF, Langhoff-Roos J, Jensen ET, Bruun B, Lind I, et al. The relationship between prior cervical conization, cervical microbial colonization and preterm premature rupture of the membranes. Eur J Obstet Gynecol Reprod Biol 1992;47:41-5.

25. Selo-Ojeme DO, Ind T, Shepherd JH. Isthmic stenosis following radical trachelectomy. J Obstet Gynaecol 2002;22:327-8.

26. Palaia I, Perniola G, Arrivi C, Sansone $M$, Pastore $M$, Calcagno M, et al. Persistent posttrachelectomy cervical stenosis treated with Petit-Le Four pessary in early cervical cancer patients: a report of two cases. Fertil Steril 2007;88:1677.e5-7. 